\title{
Protein Engineering on Human Recombinant Follistatin: Enhancing Pharmacokinetic Characteristics for Therapeutic Application ${ }^{\llbracket}$
}

\author{
Chuan Shen, Andrea Iskenderian, Dianna Lundberg, Tao He, Kathleen Palmieri, \\ Robert Crooker, Qingwei Deng, Matthew Traylor, Sheng Gu, Haojing Rong, David Ehmann, \\ Brian Pescatore, Bettina Strack-Logue, Alla Romashko, George Baviello, John Gill, \\ Bohong Zhang, Muthuraman Meiyappan, Clark Pan, and Angela W. Norton
}

Departments of Discovery Therapeutics (C.S., A.I., D.L., B.P., B.S.-L., A.R., G.B., J.G., B.Z., M.M., C.P., A.W.N.), Bioanalytical and Biomarker Development (T.H.), Discovery Biology and Translational Research (K.P., R.C., Q.D., D.E.), Analytical Development (M.T., S.G.), and Drug Metabolism and Pharmacokinetics (H.R.), Shire, Lexington, Massachusetts (H.R.)

Received February 1, 2018; accepted May 7, 2018

\section{ABSTRACT}

Follistatin (FS) is an important regulatory protein, a natural antagonist for transforming growth factor- $\beta$ family members activin and myostatin. The diverse biologic roles of the activin and myostatin signaling pathways make FS a promising therapeutic target for treating human diseases exhibiting inflammation, fibrosis, and muscle disorders, such as Duchenne muscular dystrophy. However, rapid heparin-mediated hepatic clearance of FS limits its therapeutic potential. We targeted the heparinbinding loop of FS for site-directed mutagenesis to improve clearance parameters. By generating a series of FS variants with one, two, or three negative amino acid substitutions, we demonstrated a direct and proportional relationship between the degree of heparin-binding affinity in vitro and the exposure in vivo. The triple mutation $\mathrm{K}(76,81,82) \mathrm{E}$ abolished heparinbinding affinity, resulting in $\sim 20$-fold improved in vivo exposure.
This triple mutant retains full functional activity and an antibodylike pharmacokinetic profile, and shows a superior developability profile in physical stability and cell productivity compared with FS variants, which substitute the entire heparin-binding loop with alternative sequences. Our surgical approach to mutagenesis should also reduce the immunogenicity risk. To further lower this risk, we introduced a novel glycosylation site into the heparinbinding loop. This hyperglycosylated variant showed a 10-fold improved exposure and decreased clearance in mice compared with an IgG1 Fc fusion protein containing the native FS sequence. Collectively, our data highlight the importance of improving pharmacokinetic properties by manipulating heparin-binding affinity and glycosylation content and provide a valuable guideline to design desirable therapeutic FS molecules.

\section{Introduction}

Follistatin (FS), a monomeric glycoprotein, was originally identified from porcine ovarian follicular fluid, and named for its ability to suppress pituitary follicle-stimulating hormone secretion (Robertson et al., 1987; Ueno et al., 1987). Subsequently, FS physiologic function was elucidated by its inhibition of the transforming growth factor- $\beta$ family members, mainly activins and myostatin (Hashimoto et al., 1997; Welt et al., 2002; Sidis et al., 2006; Cash et al., 2012). Activins participate in various biologic processes, including embryonic development and

https://doi.org/10.1124/jpet.118.248195.

S This article has supplemental material available at jpet.aspetjournals.org. growth, reproduction, energy metabolism, bone homeostasis, inflammation, and fibrosis (reviewed in Namwanje and Brown, 2016). Myostatin, also known as growth and differentiation factor-8, is a negative regulator of myogenesis and skeletal muscle mass (reviewed in Chen and Lee, 2016). Myostatin inhibition significantly increases skeletal muscle mass by hypertrophy (Schuelke et al., 2004; Lee et al., 2005; Latres et al., 2015; St Andre et al., 2017). FS, by antagonism of activins and myostatin, is a promising therapeutic target for human diseases associated with inflammation, fibrosis, and muscle disorders, such as Duchenne muscular dystrophy, Becker muscular dystrophy, and inclusion body myositis (Haidet et al., 2008; Kota et al., 2009; Rodino-Klapac et al., 2009; Mendell et al., 2015, 2017; Walton et al., 2017).

ABBREVIATIONS: AUC, area under the curve; BBXB, consensus heparin-binding motif (where $\mathrm{B}$ is $\mathrm{K}$ or $\mathrm{R}$, and $\mathrm{X}$ is any amino acid); $\mathrm{CHO}$, Chinese hamster ovary; cIEF, capillary isoelectric focusing; CL, clearance; FS, follistatin; FS288, human follistatin 288 isoform; FS303, human follistatin 303 isoform; FS315, human follistatin 315 isoform; FS315-hFc, human follistatin 315 isoform fused with human IgG1 Fc; FSD, follistatin domain; FS315-hFc, recombinant FS315 fused with human IgG1 Fc; $\Delta$ HBS, heparin binding sequence-deficient mutant (a 12-amino acid paralogous substitution to remove heparin-binding activity); HBS, heparin binding sequence; hFc, human IgG1 Fc; hFcRn, human neonatal Fc receptor; $K_{\mathrm{D}}$, equilibrium dissociation constant; NXT/S, N-linked glycosylation consensus sequence; PBS, phosphate-buffered saline; pl, isoelectric point; PK, pharmacokinetic; RU, response units; SPR, surface plasmon resonance; $\mathrm{V}_{\mathrm{ss}}$, steady-state volume of distribution. 
The FS gene localizes on chromosome 5q11.2. Two splice variants of FS precursors exist, a 344-amino acid precursor protein and a C-terminal truncated 317-amino acid precursor (Esch et al., 1987; Shimasaki et al., 1988). The first 29 amino acid residues are a putative signal sequence, translating as two N-terminal identical, mature FS isoforms, FS315 and FS288. Reportedly, a third FS variant, FS303, results from proteolytic cleavage of FS315 (Sugino et al., 1993). The three isoforms play different biologic roles based on differential affinities for ligands and localization. The predominant circulating isoform in human serum is FS315 (Schneyer et al., 2004), whereas FS303 predominates in ovarian follicular fluid (Sugino et al., 1993). The domain structure of FS is composed of a 63-residue $\mathrm{N}$-terminal domain, three successive FS domains (FSDs) (FSD1, FSD2, and FSD3), and an acidic C-terminal tail in FS315 and FS303 isoforms (Fig. 1). The three FSDs ( $\sim 50 \%$ primary sequence homology) can be aligned by their 10 cysteine residues. Intradomain disulfide linkages allow each FSD autonomous folding (Innis and Hyvonen, 2003).

FS interaction with heparin affinity columns and proteoglycan heparan sulfate on cell surfaces were described in early characterization studies (Ueno et al., 1987; Nakamura et al., 1991). Later studies identified a core heparin-binding sequence (HBS) in FS, a highly basic 12-residue segment (residues 75-86) located in the FSD1 domain (Inouye et al., 1992; Innis and Hyvonen, 2003). The HBS region contains two consensus heparin-binding motifs BBXB (Fig. 1), where B is K or R. Amino acid substitution in the HBS can reduce FS binding to heparin (Sidis et al., 2005). In recent studies, an engineered FS315, with a paralogous substitution to remove HBS fused to a murine IgG1 Fc domain, significantly improved exposure and half-life in mice, displaying dosedependent pharmacological effects in a model of muscle atrophy (Datta-Mannan et al., 2013; Yaden et al., 2014). Thus, therapeutically relevant FS variants are possible by targeting the HBS domain. To develop desirable molecules with limited mutagenesis, and to correlate the degree of heparin-binding affinity to the pharmacokinetic (PK) behavior of recombinant FS315 fused with human IgG1 Fc (FS315-hFc), we mutated basic residues in BBXB motifs to attain varying heparinbinding affinities. These data illustrate a direct and proportional relationship between the degree of heparin binding

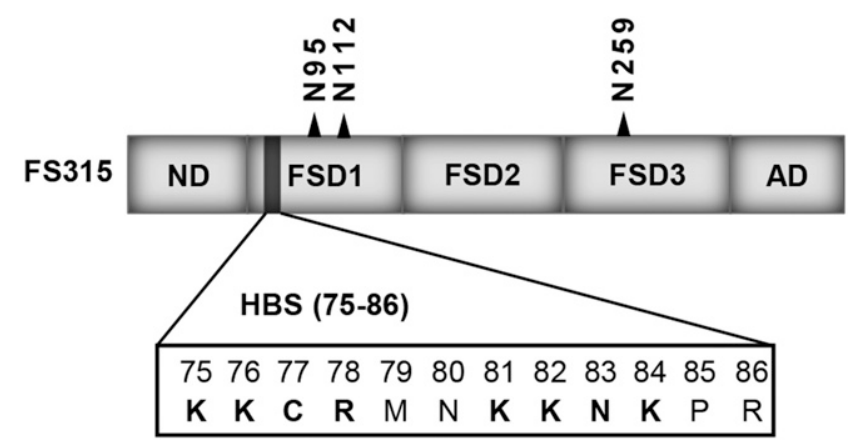

Fig. 1. Protein domain structure of FS315. FS315 is composed of an N-terminal domain (ND), three successive FSDs with high homology (FSD1, FSD2, and FSD3), and a highly acidic C-terminal tail (AD). The HBS is located in the FSD1, and two conserved basic heparin-binding core motifs are shown in bold. The positions of three endogenous N-linked glycosylation sites are indicated by solid triangles. in vitro and systemic exposure in vivo. We demonstrate that selective negative charge substitutions to BBXB motifs can dramatically affect the heparin-binding affinity.

During the past decade, recombinant proteins have become an important portion of new biopharmaceutical products. Glycoengineering to influence the glycosylation state has been used to improve recombinant protein properties such as increased stability, prolonged half-life, and decreased immunogenicity (Jefferis, 2016; Lalonde and Durocher, 2017). Introducing novel glycosylation sites into the recombinant FS heparin-binding loop to modulate carbohydrate content, block heparin binding, and reduce the mutagenesis immunogenicity risk is largely unexplored. In this study, we introduced new N-linked glycosylation consensus sequences (NXT/Ss) into the HBS region of recombinant FS315-hFc for potential hyperglycosylation. Our data showed that the K75N/C77T mutation effectively resulted in hyperglycosylation of the FS fusion protein and significantly improved in vivo systemic exposure.

\section{Materials and Methods}

\section{Construction, Expression, and Purification of Recombinant FS Variants}

Human FS315 coding sequence was cloned from Human Liver Quick-clone cDNA (Clontech, Mountain View, CA). Human IgG1 Fc (hFc) fragment was cloned from the Human Adult Normal Lung cDNA Library (Life Technology, Carlsbad, CA), and L residues on positions 14 and 15 in the $\mathrm{hFc}$ region were further changed to $\mathrm{A}$ by mutagenesis to reduce the affinity to Fc- $\gamma$-receptor. FS315 and hFc fragments were subsequently cloned in frame into a mammalian expression vector. For each of the FS315-hFc variants, a mutated DNA sequence in the HBS region was synthesized by ATUM (Newark, CA), and replaced the wild-type HBS region. The recombinant FS315-hFc variant plasmids were transfected into Chinese hamster ovary (CHO) cells (Sigma-Aldrich, St. Louis, MO) by electroporation. The cells were tested as mycoplasma free, were cultured in EX-Cell CD CHO Fusion media (Sigma-Aldrich) under standard conditions $\left(5 \% \mathrm{CO}_{2}, 37^{\circ} \mathrm{C}\right)$, and were selected for 10 days to generate stable pools. FS315-hFc-variant proteins stably secreted in cell culture supernatant were captured onto a HiTrap MabSelect SuRe column (GE Healthcare Bio-Sciences Corp., Piscataway, NJ) in $1 \times$ phosphate-buffered saline (PBS; pH 7.4), and eluted using a step gradient of $10 \mathrm{mM}$ sodium citrate $(\mathrm{pH} 2.5)$. The proteins were neutralized to $\mathrm{pH} 7.0$ by adding $1 \mathrm{M}$ Tris buffer ( $\mathrm{pH} 9.0$ ). Impurities were further removed using a Superdex 200 26/600 Column (GE Healthcare Bio-Sciences Corp.). Purity of the final proteins was $>95 \%$, as analyzed by size exclusion chromatography analysis using a model 2996 PDA Detector (Waters, Milford, MA).

\section{Surface Plasmon Resonance Binding Assay}

Binding affinities of FS315-hFc variants to heparin, myostatin and human neonatal Fc receptor ( $\mathrm{hFcRn}$ ) were determined using surface plasmon resonance (SPR) methods on a Biacore T200 instrument (GE Healthcare BioSciences Corp.).

Heparin SPR Binding Assay. Biotinylated heparin (SigmaAldrich) was resuspended in $1 \times$ HBS-N buffer (10 mM HEPES and $150 \mathrm{mM}$ sodium chloride, $\mathrm{pH}$ 7.4) and used fresh for binding studies. A Biacore streptavidin sensor chip (GE Healthcare Bio-Sciences Corp.) was prepared following the product instructions, and biotinylated heparin was loaded to a response of approximately 40 response units (RU). All FS315-hFc samples were serially diluted in $1 \times$ HBS$\mathrm{EP}+$ buffer (10 mM HEPES, $150 \mathrm{mM}$ sodium chloride, $3 \mathrm{mM}$ EDTA, and $0.05 \% \mathrm{v} / \mathrm{v}$ Surfactant $\mathrm{P} 20, \mathrm{pH} 7.4$ ) to a range of $0-25 \mathrm{nM}$ for kinetic experiments. The association time and dissociation time were set to 
300 seconds at a flow rate of $30 \mu \mathrm{l} / \mathrm{min}$. The chip surface was regenerated between runs using $4 \mathrm{M}$ sodium chloride. Kinetic data were fit using a 1:1 binding model.

Myostatin SPR Binding Assay. A single-cycle kinetics method was used for myostatin binding. A CM5 series S sensor chip (GE Healthcare Bio-Sciences Corp.) with anti-hFc antibody immobilized to about 10,000 RU was used to capture all FS315-hFc variants. Myostatin (R\&D Systems, Minneapolis, MN) was used as analyte in the range of $0-5 \mathrm{nM}$ for kinetic experiments. A 5-minute association step was used for each dilution followed by a 40-minute dissociation. The chip surface was regenerated using $3 \mathrm{M}$ magnesium chloride between experiments.

hFcRn SPR Binding Assay. hFcRn was purified from human embryonic kidney 293 cells stably expressing $\mathrm{hFcRn}$. hFcRn was immobilized on a CM5 series $\mathrm{S}$ sensor chip (GE Healthcare BioSciences Corp.) with a target of approximately 500 RU. The FS315$\mathrm{hFc}$ samples were serially diluted in $1 \times \mathrm{PBS}-\mathrm{P}+$ buffer $(20 \mathrm{mM}$ phosphate buffer, $2.7 \mathrm{mM}$ potassium chloride, $137 \mathrm{mM}$ sodium chloride, and $0.05 \%$ Surfactant P20, pH 5.5) to a range of 0-100 nM, and were used as analytes for multicycle kinetic experiments. The association and dissociation times were set at 300 seconds, each at a flow rate of $30 \mu \mathrm{l} / \mathrm{min}$. A 1:1 binding model was used to fit the data.

\section{Capillary Isoelectric Focusing Assay}

The protein charge heterogeneity was monitored by capillary isoelectric focusing (cIEF) analytical technique using a Peggy Sue instrument (ProteinSimple, San Jose, CA) as described by the vendor. Briefly, each of the FS315-hFc variants was diluted to $0.01 \mathrm{mg} / \mathrm{ml}$ in $10 \mathrm{M}$ Urea Buffer (Life Technology), diluted 4-fold with Premix/ladder mixture (ProteinSimple), and loaded $12 \mu \mathrm{l} /$ well. Procedures were run in triplicate for each sample. Anti-FS antibody (catalog number ab47941; Abcam, Cambridge, MA) and anti-Rabbit IgG (H\&L), HRP conjugate (catalog number W4011; Promega, Madison, WI) were diluted to 1:100 and used for detection.

\section{SMAD-Responsive Luciferase Reporter Gene Assay}

The human rhabdomyosarcoma cell line A204 (catalog number HTB-82; American Type Culture Collection, Manassas, VA) was stably transfected with a SMAD-responsive luciferase reporter construct pGL3(CAGA)12, as described previously (Dennler et al., 1998; Sako et al., 2010). The A204 stable cells were tested as mycoplasma free, and seeded at 40,000 cells/well per $100 \mu \mathrm{l}$ into a white Corning costar 96-well plate (Corning Life Sciences, Bedford, MA) in growth medium composed of McCoy's 5A medium (Life Technology), 10\% dialyzed fetal bovine serum (Life Technology), and $320 \mu \mathrm{g} / \mathrm{ml}$ Geneticin (Life Technology) at $37^{\circ} \mathrm{C}$ and in $5 \% \mathrm{CO}_{2}$ overnight for 16 hours. The next day, $2.4 \mathrm{nM}$ myostatin (R\&D Systems) or $2.4 \mathrm{nM}$ activin $\mathrm{A}$ (R\&D Systems) and serial dilutions (1:3) of FS315-hFc variants ranging from 0 to $20 \mathrm{nM}$ were made separately in A204 assay medium composed of McCoy's 5A medium (HyClone, Logan, UT) and $0.1 \%$ bovine serum albumin (Thermo Fisher Scientific, Waltham, MA). Each concentration of the FS315-hFc variants was mixed well with an equal volume of $2.4 \mathrm{nM}$ myostatin or $2.4 \mathrm{nM}$ activin A at room temperature for 30 minutes. Upon complete aspiration of the growth medium from the white 96-well cell plate, $100 \mu \mathrm{l}$ of the mixture was immediately added into individual wells of the plate. The cell plate was incubated for 20 hours at $37^{\circ} \mathrm{C}$. The next day, $100 \mu \mathrm{l} /$ well of ONE-Glo luciferase assay system (Promega) was directly added into individual wells of the cell plate, and the luminescence signal from the cell plate was measured in a FlexStation 3 instrument (Molecular Devices, Sunnyvale, CA). The induction of a SMAD-responsive reporter (i.e., $100 \%$ signals) was produced by either $2.4 \mathrm{nM}$ myostatin or $2.4 \mathrm{nM}$ activin alone, and the negative control (i.e., $0 \%$ signals) was produced by A204 assay medium alone. IC $_{50}$ curves were fitted using GraphPad Prism software (GraphPad Software, Inc., La Jolla, CA).

\section{Glycan Analysis}

Protein samples were analyzed as described previously (Traylor et al., 2016) with a few differences. Samples were alkylated with iodoacetamide (Thermo Fisher Scientific) and digested only with sequencing-grade endoprotease Lys-C (Roche Diagnostics, RischRotkreuz, Switzerland). Analyses were performed with an Acquity Classic UPLC System (Waters) with an inline QExactive Plus Orbitrap or an LTQ Orbitrap Velos mass spectrometer (Thermo Fisher Scientific). Samples were separated on a CSH300 $2.1 \times 100 \mathrm{~mm}$ chromatography column with $1.7-\mu \mathrm{m}$ particles (Waters).

Mass spectrometry data were analyzed with PepFinder 2.0 (Thermo Fisher Scientific). A modification list was generated using the default software parameters and exported into Microsoft (Redmond, WA) Excel. The identified glycan modifications were used to calculate sialic acid content in units of moles of sialic acid per mole of oligosaccharide. For each identified glycan modification, the percentage of abundance was multiplied by the number of sialic acid units on the oligosaccharide and was divided by the glycan occupancy to normalize the calculation to the total quantity of oligosaccharide at the particular site. The sum of this quantity for all identified glycans at an N-linked site yields the sialic acid abundance in units of moles of sialic acid per mole of oligosaccharide. If an oligosaccharide is present (i.e., the site is occupied), the sialic acid content value provides the average quantity of sialic acid on the oligosaccharide. The percentage of asialylated oligosaccharide was calculated by adding all the percentages of the oligosaccharide species without terminal sialic acid together then dividing this value by the oligosaccharide occupancy at the particular glycosylation site. The percentage of different antennary (branch) structures was calculated similarly by adding the percentage of oligosaccharides with particular antennary structures (e.g., bi-, tri-, tetraantennary) and then dividing that value by the oligosaccharide occupancy at the particular glycosylation site.

\section{Polyacrylamide Gel Electrophoresis and Coomassie Blue Staining}

Three micrograms of a purified recombinant FS315-hFc protein sample was mixed with a Bond-Breaker Tris(2-carboxyethyl)phosphine hydrochloride solution (Thermo Fisher Scientific) and NuPAGE LDS Sample Buffer $(4 \times)$ (Life Technology), and then incubated at $37^{\circ} \mathrm{C}$ for 15 minutes. The mix was run on a NuPAGE Novex 4\%-12\% gradient Bis-Tris gel (Life Technology) for 35 minutes at $190 \mathrm{~V}$ in NuPAGE Novex MES SDS Running Buffer (Life Technology). The Coomassie Blue staining was carried out using InstantBlue (Expedeon, San Diego, CA) by following the instructions.

\section{Murine PK Studies}

CD-1 female mice at 4-5 weeks of age were obtained from Charles River Laboratories (Wilmington, MA). Mice were housed in groups of three per cage under a 12-hour light/dark cycle, and targeted humidity $(50 \% \pm 20 \%)$ and temperature $\left(22 \pm 3^{\circ} \mathrm{C}\right)$. Rodent diet (Laboratory Rodent Diet 5001; LabDiet, St. Louis, MO) and water (Lexington, MA, municipal water purified by reverse osmosis) was available ad libitum for the duration of the experiment. The care of animals was conducted in accordance with the guidelines described in the Guide for the Care and Use of Laboratory Animals (The National Academies Press, Washington D.C.). All in vivo procedures described were approved by Shire Pharmaceuticals Institutional Animal Care and Use Committee.

Animals were handled with aseptic technique and were placed in a restrainer for intravenous injection. The site was wiped with $70 \%$ ethanol, and the tail vein was dilated by flicking the tail gently with the finger. All FS315-hFc variants, diluted in $1 \times \mathrm{PBS}(\mathrm{pH} 7.4)$, were injected into the vein using a 28 -gauge insulin syringe to a final dosing volume of $1 \mathrm{mg} / \mathrm{kg}$ individually. At each time point, three animals were euthanized using carbon dioxide inhalation, and cardiac puncture was used to collect a blood sample. Blood was added to a serum separator tube and centrifuged for 3 minutes at 13,200 rpm, and serum was collected in an Eppendorf tube and frozen at $-80^{\circ} \mathrm{C}$.

\section{Immunoassays for the PK Samples and PK Data Analysis}

Serum concentrations of FS315-hFc variants were determined using an electro-chemiluminescent immunoassay. Meso Scale 
Discovery standard plates (MSD, Rockville, MD) were coated with 10.0 $\mu \mathrm{g} / \mathrm{ml}$ goat anti-human FS antibody (AF669; R\&D Systems) in $1 \times$ PBS, $30 \mu \mathrm{l} /$ well. After overnight incubation at $4^{\circ} \mathrm{C}$, plates were washed three times with wash buffer $(20 \%$ Tween- 20 in $1 \times$ PBS) and then blocked with $150 \mu \mathrm{l} /$ well blocking buffer $(2.5 \%$ bovine serum albumin, $0.05 \%$ Casein in $1 \times$ PBS) and incubated at $25^{\circ} \mathrm{C}$ for 1 hour with shaking. After washing three times with wash buffer, samples and a standard curve of FS315-hFc variants ranging from 0.98 to $125 \mathrm{ng} / \mathrm{ml}$ were added, $25 \mu \mathrm{l} / \mathrm{well}$. Samples, controls and standards were incubated at $25^{\circ} \mathrm{C}$ for 1 hour with shacking. After washing three times with wash buffer, $25 \mu \mathrm{l} / \mathrm{well}$ of $2.5 \mu \mathrm{g} / \mathrm{ml}$ mouse anti human IgG1-Fc (Abcam) labeled using Gold Sulfo-Tag NHS Ester (R91AO; MSD) was added. After incubation at $25^{\circ} \mathrm{C}$ for 1 hour with shaking, and washing three times with wash buffer, $1 \times$ Read Buffer $\mathrm{T}$ (R92TC; MSD) was added, $150 \mu \mathrm{l} /$ well. Plates were read with a SECTOR imager (MSD) and concentrations determined relative to the standard curve, adjusted for dilutions.

Noncompartmental PK analysis of serum concentration data of FS315-hFc variants was performed using Phoenix WinNonlin (version 6.3; Pharsight Corporation, Mountain View, CA). PK parameters such as systemic terminal half-life (which was determined using the last four time points), clearance (CL), steady-state volume of distribution $\left(\mathrm{V}_{\mathrm{ss}}\right)$, and area under the curve (AUC) were calculated.

\section{Results}

The Charge of the Basic BBXB Motifs within the FS HBS Affects the Heparin-Binding Affinity. Rapid heparin-mediated hepatic CL of native FS, even when fused to the antibody $\mathrm{Fc}$ fragment, limits its therapeutic potential as shown from published data (Datta-Mannan et al., 2013) and our unpublished data (data not shown). To overcome this limitation, we targeted the heparin-binding loop of FS for modulating heparin-binding activity by site-directed mutagenesis. Sidis et al. (2005) previously showed that the mutations of $\mathrm{K}$ residues within the FS288 isoform heparinbinding motifs $[(\mathrm{K}(75,76) \mathrm{A}, \mathrm{K}(81,82) \mathrm{A}$, and $\mathrm{K}(76,81,82) \mathrm{A})]$ resulted in decreased heparin binding in a competition assay. We first hypothesized that the substitution of positive charged residues within two BBXB motifs with amino acids having a negative charge will result in an even greater heparin-binding decrease than seen with A substitutions. To test this hypothesis, we generated $\mathrm{K}(81,82) \mathrm{E}, \mathrm{K}(81,82) \mathrm{D}, \mathrm{K}(76,81,82) \mathrm{E}$, and $\mathrm{K}$ $(76,81,82) \mathrm{D}$ variants to compare with $\mathrm{K}(81,82) \mathrm{A}$ and $\mathrm{K}$ $(76,81,82)$ A. Because of the poor expression of FS288 in our study, which was also reported by others (Datta-Mannan et al., 2013), all the variants were recombinant proteins of the FS315 isoform fused to $\mathrm{hFc}(\mathrm{FS} 315-\mathrm{hFc})$ directly. The protein sequence of $\mathrm{hFc}$ region used in this study is shown in Supplemental Material. The binding interaction between FS315-hFc variants and heparin was measured using SPR method. The binding affinities were measured and reported by the equilibrium dissociation constant $\left(K_{\mathrm{D}}\right)$ (Supplemental Table 3; Table 1). After substitution to more negative residues, both $\mathrm{K}(81,82) \mathrm{E}$ and $\mathrm{K}(81,82) \mathrm{D}$ had $>7$-fold reductions in heparin binding compared with $\mathrm{K}(81,82) \mathrm{A}$, indicating the further impaired heparin-binding activity. Consistently, the triplet variants $\mathrm{K}(76,81,82) \mathrm{E}$ and $\mathrm{K}(76,81,82) \mathrm{D}$ also had highly reduced affinities compared with $\mathrm{K}(76,81,82) \mathrm{A}$. Molecules containing both $\mathrm{E}$ and $\mathrm{D}$ triplet variants had no detectable heparin binding in our testing range (up to $25 \mathrm{nM}$ ). However, the heparin SPR binding $K_{\mathrm{D}}$ was $9.4 \mathrm{nM}$ for $\mathrm{K}$ $(76,81,82) \mathrm{A}$, having either comparable or even stronger affinity than the doublet $\mathrm{K}(81,82) \mathrm{E}$ and $\mathrm{K}(81,82) \mathrm{D}$ variants. These data support our hypothesis that changing the charge of the basic BBXB motifs within the FS HBS significantly affects the binding affinity to heparin.

Extent and Position of Glutamic Acid (E) Substitutions in Two Basic BBXB Motifs Affect the HeparinBinding Affinity. Our above data also suggested that the triplet $\mathrm{K}(76,81,82) \mathrm{E}$ and $\mathrm{K}(76,81,82) \mathrm{D}$ variants that altered two BBXB motifs showed greater reduction on affinities compared with doublet $\mathrm{K}(81,82) \mathrm{E}$ and $\mathrm{K}(81,82) \mathrm{D}$ variants, which only altered one of the two BBXB motifs, indicating that both motifs contribute to the heparin binding (Table 1). To further understand the role of the key basic residues within the two BBXB motifs on the heparin-binding affinity, we generated a series of FS315-hFc variants in which we replaced one, two, or three basic residues with negatively charged $\mathrm{E}$

TABLE 1

In vitro analytical data for heparin binding variants of $\mathrm{FS} 315-\mathrm{hFc}$

The binding of recombinant FS315-hFc variants to heparin, myostatin, or hFcRn was determined by SPR. The binding affinities were measured and reported as the $K_{\mathrm{D}}$. The charge heterogeneity of the variants was determined by cIEF and was shown as a range of pI values. The statistical parameters and analysis, including association constant $\left(k_{\mathrm{a}}\right)$ with S.E., dissociation constant $\left(k_{\mathrm{d}}\right)$ with S.E., and the average $K_{\mathrm{D}}$ values with S.D. ( $n=4$ independent batches) for an internal control used in all SPR assays, are reported in Supplemental Table 3. ND*: No detectable heparin binding in tested concentration ranges of 0.019-25 nM FS315-hFc variants.

\begin{tabular}{llcccc}
\hline \multirow{2}{*}{ FS315-hFc Variant } & & Heparin Binding $K_{\mathrm{D}}$ & Myostatin Binding $K_{\mathrm{D}}$ & $\mathrm{hFcRn} \mathrm{Binding} K_{\mathrm{D}}$ & $\mathrm{cIEF}$ \\
\hline & & $\mathrm{nM}$ & $\mathrm{pM}$ & $\mathrm{nM}$ & $\mathrm{pI}$ \\
Controls & Wild type & 0.2 & 20.2 & 31.4 & $5.07-5.89$ \\
& SHBS & $\mathrm{ND}$ & 17.4 & 48.0 & $4.82-5.72$ \\
One-amino acid substitution & del75-86 & $\mathrm{ND}$ & 57.1 & 38.8 & $4.83-5.26$ \\
& $\mathrm{~K} 84 \mathrm{E}$ & 0.9 & 9.9 & 34.9 & $5.07-6.01$ \\
Two-amino acid substitution & $\mathrm{K} 82 \mathrm{E}$ & 1.5 & 11.9 & 10.5 & $5.48-6.09$ \\
& $\mathrm{~K}(76,84) \mathrm{E}$ & 0.8 & 9.0 & 33.0 & $4.87-5.95$ \\
& $\mathrm{R} 78 \mathrm{E} / \mathrm{K} 84 \mathrm{E}$ & 0.8 & 7.2 & 45.5 & $5.06-5.96$ \\
& $\mathrm{~K}(75,76) \mathrm{E}$ & 1.1 & 11.7 & 34.2 & $5.05-5.26$ \\
& $\mathrm{~K}(82,84) \mathrm{E}$ & 1.1 & 9.0 & 45.1 & $4.86-5.95$ \\
& $\mathrm{R} 78 \mathrm{E} / \mathrm{K} 82 \mathrm{E}$ & 1.3 & 3.9 & 53.3 & $4.96-5.96$ \\
& $\mathrm{~K}(81,82) \mathrm{A}$ & 1.5 & 11.9 & 38.5 & $5.31-5.96$ \\
& $\mathrm{~K}(76,82) \mathrm{E}$ & 3.9 & 10.5 & 38.2 & $4.89-5.26$ \\
& $\mathrm{~K}(81,82) \mathrm{E}$ & 10.7 & 9.9 & 40.8 & $4.83-5.25$ \\
& $\mathrm{~K}(81,82) \mathrm{D}$ & 20.6 & 7.1 & 24.7 & $4.88-5.59$ \\
Three-amino acid substitution & $\mathrm{K}(76,81,82) \mathrm{A}$ & 9.4 & 11.3 & 41.6 & $5.24-5.93$ \\
& $\mathrm{~K}(76,82,84) \mathrm{E}$ & 13.8 & 4.7 & 50.8 & $4.85-5.80$ \\
& $\mathrm{~K}(76,81,82) \mathrm{E}$ & $\mathrm{ND}$ & 4.2 & 44.0 & $4.87-5.80$ \\
& $\mathrm{~K}(76,81,82) \mathrm{D}$ & $\mathrm{ND}$ & 5.9 & 59.9 & $4.82-5.67$ \\
\hline
\end{tabular}


within BBXB motifs. We also generated the following two recombinant heparin binding-deficient variants with larger changes: 1) FS315 $\Delta$ HBS-hFc, an HBS replacement variant $\Delta$ HBS in which the HBS (residues 75-86) was replaced by the corresponding segment from FSD2 (residues 148-159) that lacks any heparin-binding capability as described by Sidis et al. (2005); and 2) FS315del75-86-hFc, a HBS deletion variant del75-86 in which the core 12-amino acid HBS was deleted. The recombinant wild-type FS315 isoform fused with hFc, which had similar potency to myostatin and activin as native FS315 (catalog number 4889-FN/CF; R\&D Systems) in our cell-based assay (unpublished data), was named as "wild type" and used as the control in this study. The HBS sequences for wild type and all heparin-binding variants are listed in Supplemental Table 1. The SPR binding data showed that all of the variants with one, two, or three E substitutions had reduced heparin affinities to different degrees compared with wild type (4-fold to 100-fold reduction or undetectable binding in our testing range) (Table 1). In general, increasing the extent of $\mathrm{E}$ substitutions progressively decreased the heparin binding. For example, the heparin binding $K_{\mathrm{D}}$ values were 1.5, $10.7 \mathrm{nM}$, and undetectable binding in the tested range for $\mathrm{K} 82 \mathrm{E}, \mathrm{K}(81,82) \mathrm{E}$ and $\mathrm{K}(76,81,82) \mathrm{E}$ variants, respectively. $\mathrm{K}$ $(76,81,82) \mathrm{E}, \Delta \mathrm{HBS}$, and del75-86 variants all showed similar abolished heparin binding (Table 1), indicating that FS heparin-binding affinities can be effectively abolished with three negatively charged point mutations.

By systematically evaluating the different variants, an additional two conclusions can be drawn about the role of basic residues in two FS BBXB motifs. First, the second BBXB motif KKNK (residues 81-84) clearly plays a more dominant role in heparin binding than the first BBXB motif KKCR (residues 75-78), as indicated by $\mathrm{K}(81,82) \mathrm{E}\left(K_{\mathrm{D}} 10.7 \mathrm{nM}\right)$ having $\sim 10$-fold weaker binding compared with $\mathrm{K}(75,76) \mathrm{E}\left(K_{\mathrm{D}}\right.$ $1.1 \mathrm{nM}$ ) (Table 1). Second, the third basic residue in each of FS BBXB motifs has much less effect on heparin binding. Our data (Table 1) showed that 1) a doublet variant $\mathrm{K}(76,82) \mathrm{E}$ with the second basic residue mutations in both motifs had 5 -fold weaker binding than a doublet variant R78E/K84E with the third basic residue mutations in both motifs; and 2) adding mutations of the third basic residue from each motif (R78E and $\mathrm{K} 84 \mathrm{E}$ ) to the $\mathrm{K} 82 \mathrm{E}$ variant did not affect the binding affinity, as the $K_{\mathrm{D}}$ values for $\mathrm{K} 82 \mathrm{E}$, R78E/K82E, and $\mathrm{K}(82,84)$ E were 1.5, 1.3, and 1.1 nM, respectively; and 3) the $\mathrm{K}(81,82) \mathrm{E}$ variant binds to heparin $\sim 10$-fold weaker than the $\mathrm{K}(82,84) \mathrm{E}$ variant, 10.7 versus $1.1 \mathrm{nM}$, and $\mathrm{K}(76,81,82) \mathrm{E}$ also had much weaker binding affinity than $\mathrm{K}(76,82,84) \mathrm{E}$, indicating a minor role of K84. All the data demonstrated that the first two basic residues are more important than the third basic residue in FS BBXB motifs for heparin binding. Taken together, our data above demonstrate that the number of mutations and their positions, and the charge of the residue affect the heparinbinding affinity.

In Vitro Ligand Binding and Functional Properties for Heparin-Binding Variants. In contrast to the large differences observed for heparin-binding affinities among FS315-hFc variants substituted with negatively charged amino acids (4-fold to $>100$-fold reduction compared with wild type), the variants exhibited little change in binding affinity to myostatin. The $K_{\mathrm{D}}$ values determined by the SPR method are summarized in Table 1. Uniquely, several of the heparin-binding variants had moderately improved myostatin-binding affinities by SPR assay (1.5-fold to 5-fold increase compared with wild type). The HBS deletion variant del75-86 performed differently, which showed a 3-fold reduction compared with wild type. To test whether the variants change FS biologic function, we selected a subset of variants and tested their inhibition of myostatin- and activin A-induced SMAD signaling using a SMAD-responsive luciferase reporter assay in A204 rhabdomyosarcoma cells. For all heparinbinding variants with the one-, two-, or three-point mutations, the potencies of inhibiting myostatin signaling or activin signaling were similar, and comparable to wild type (Fig. 2A; Table 2). The HBS deletion (del75-86) variant showed more than 10-fold reduction in both myostatin inhibition and activin inhibition compared with wild type in the cell-based assay (Table 2). The weaker affinity between the del75-86 variant and its ligands caused unsaturated and extended $\mathrm{IC}_{50}$ curves (Fig. 2A). However, we did not see any functional reduction for the HBS replacement variant $\Delta \mathrm{HBS}$ (Table 2), suggesting that the deletion of amino acids 75-86 may change the conformation of the molecule.

We also tested whether the mutations in the BBXB motifs affect the interaction between the hFc portion of our recombinant variants and $\mathrm{hFcRn}$ by SPR under acidic condition. With the mutations located in the HBS region in FSD1 and the hFc portion fused to the $\mathrm{C}$ terminus, there were no obvious affinity changes to $\mathrm{hFcRn}$ for our heparin-binding variants compared with wild type (Table 1). The isoelectric point (pI) values for most of our variants with the negatively charged amino acid substitutions, as well as for the $\Delta \mathrm{HBS}$ and del75-86 variants, were clearly shifted to the acidic range (Table 1).

Binding Affinity to Heparin Affects In Vivo PK Profile. As described above, by rational mutagenesis of the basic BBXB motifs, we were able to generate a series of variants with different in vitro heparin-binding affinities. Heparin binding is a surrogate for the association with cell surface heparan sulfate proteoglycans, which is a critical process for internalization and CL for many proteins in vivo (Bernfield et al., 1999). We were interested to investigate the effect of modulated heparin-binding affinity on PK profiles in mice. Selected HBS variants with different heparin-binding affinities were administered as single intravenous doses $(1 \mathrm{mg} / \mathrm{kg})$ to female CD1 mice. The serum exposures of these molecules were monitored up to 168 hours after dosing. After a single $1 \mathrm{mg} / \mathrm{kg}$ i.v. dose, wild type had a CL rate and half-life of $30 \mathrm{ml} / \mathrm{h}$ per kilogram and 68 hours, respectively, and the $\Delta$ HBS variant had a much lower CL and longer half-life of $1.3 \mathrm{ml} / \mathrm{h}$ per kilogram and 92 hours, respectively (Table 3), which is consistent with previously published data (Datta-Mannan et al., 2013). All of the tested newly designed heparin-binding variants showed improved PK profiles compared with the wild type (Fig. 3; Table 3). Strikingly, we observed a clear correlation between the degree of heparin-binding affinity in vitro and the exposure measured as the AUC in vivo. Diminishing in vitro heparinbinding affinity correlated with a progressively increased AUC (Fig. 3A) and a progressively decreased CL (Fig. 3B) compared with wild type, ranging from a 2 -fold to a 25 -fold shift for tested variants. The $\mathrm{V}_{\mathrm{ss}}$ values were highly decreased for the heparinbinding variants compared with wild type (Table 3 ), indicating that reducing heparin-binding affinity had a significant impact on the apparent volume of distribution, which should be mainly caused by a decreased association with cell surface heparan sulfate proteoglycans. The data above clearly demonstrate the 
A $\quad 1.2 \mathrm{nM}$ Myostatin stimulation

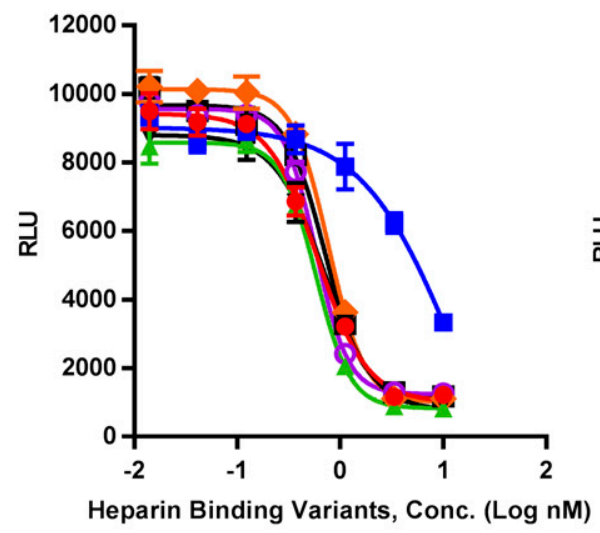

1.2 nM Activin A stimulation

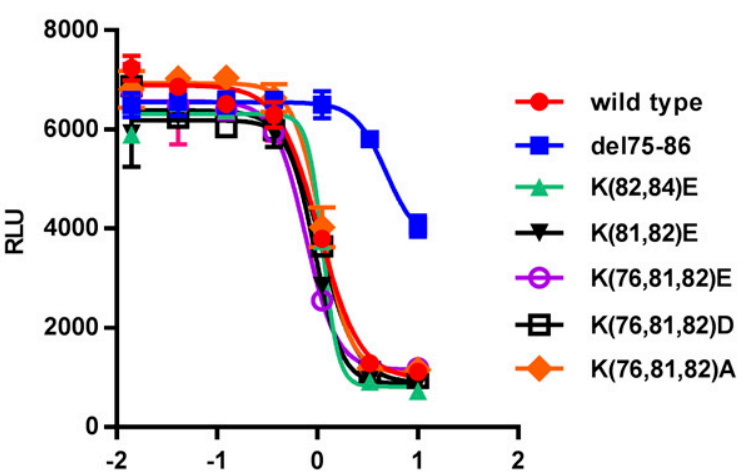

Heparin Binding Variants, Conc. (Log nM)
B 1.2 $\mathrm{nM}$ Myostatin Stimulation

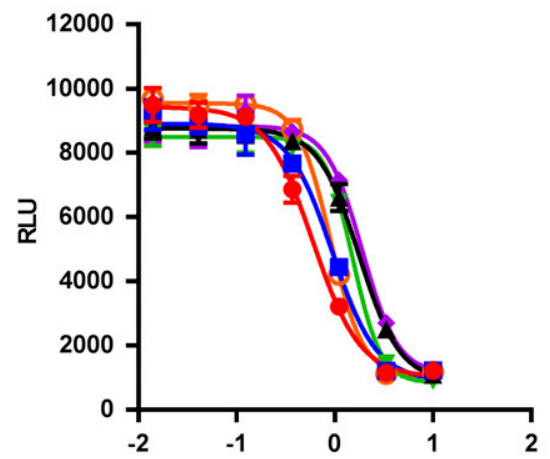

Hyperglycosylation Variants, Conc. (Log nM)

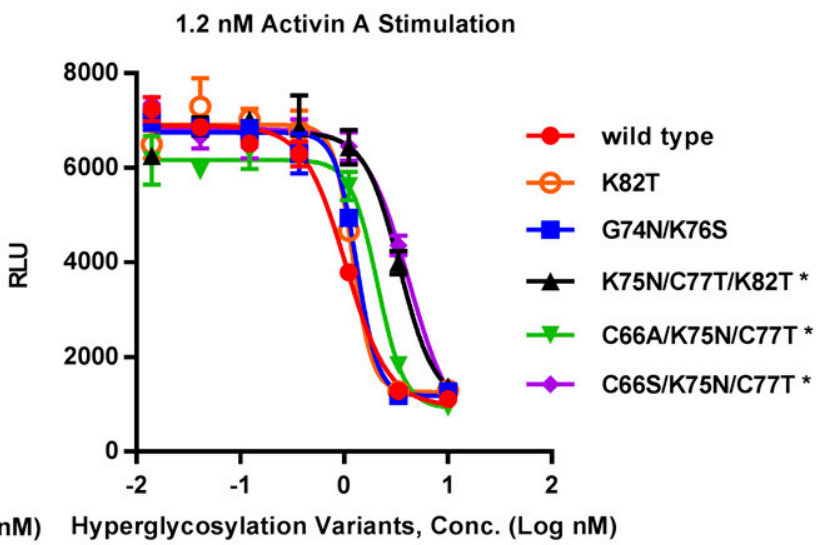

Hyperglycosylation Variants, Conc. (Log nM)

* Indicates hyperglycosylated FS315-hFc variants.

Fig. 2. In vitro cell-based functional assay. The inhibition of myostatin and activin A was investigated using a SMAD-responsive luciferase reporter assay in A204 rhabdomyosarcoma cells. (A) $\mathrm{IC}_{50}$ curves of myostatin and activin A for representative FS315-hFc heparin-binding variants. Single, double, and triple mutations had no effect on functional activities, but the HBS del75-86 variant had greatly reduced potency. (B) IC $_{50}$ curves of myostatin and activin A for representative FS315-hFc hyperglycosylation variants. The three hyperglycosylated variants $\mathrm{K} 75 \mathrm{~N} / \mathrm{C} 77 \mathrm{~T} / \mathrm{K} 82 \mathrm{~T}$, $\mathrm{C} 66 \mathrm{~A} / \mathrm{K} 75 \mathrm{~N} / \mathrm{C} 77 \mathrm{~T}$, and $\mathrm{C} 66 \mathrm{~S} / \mathrm{K} 75 \mathrm{~N} / \mathrm{C} 77 \mathrm{~T}$ had moderate reduction in potency. Conc., concentration.

critical impact of the heparin binding on the in vivo PK properties.

Datta-Mannan et al. (2013) previously reported that a recombinant FS heparin binding-deficient mutant, with a paralogous substitution to remove the heparin-binding loop, had $\sim 8$-fold and $\sim 3$-fold improved AUC and half-life values, respectively, compared with the recombinant wild-type FS in mice. In our studies, variant $\mathrm{K}(76,81,82) \mathrm{E}$ with no measurable heparin binding had $\sim 20$-fold improved AUC and $\sim 2$-fold improved half-life compared with the recombinant wild type, and even had moderately improved AUC and half-life compared with $\triangle$ HBS variant in mice (Table 3 ). In addition, $\mathrm{K}$ $(76,81,82) \mathrm{E}$ also showed better developability properties compared with the $\triangle \mathrm{HBS}$ variant in our studies, including increased protein expression and reduced aggregation (data not shown). Based on the improved PK profile and developability characteristics described here, the recombinant $\mathrm{K}$ $(76,81,82) \mathrm{E}$ variants (fused with either human Fc or murine Fc) were used for pharmacodynamics studies, and resulted in significantly increased muscle mass and functional improvement in a dose-dependent manner (Shire, manuscript in preparation).
Novel N-Linked Glycosylation Consensus Sequences Introduced for Hyperglycosylation. In our study, we also used a more surgical approach to the mutagenesis described above to generate potentially hyperglycosylated recombinant FS315-hFc variants by introducing new NXT/Ss into the heparin-binding loop. Our rationale for this approach included reducing immunogenicity risk; modulating the carbohydrate content to decrease CL; and blocking heparin binding by adding a negatively charged, bulky glycan structure. We designed 10 new variants representing six consensus N-linked glycosylation sites, NXT/Ss, where X can be any amino acid except proline, on positions $74,75,78,80,83$, and 86 within the HBS region (sequences are listed in Supplemental Table 2). Initial detection of the incorporation of additional carbohydrate moiety was observed by the molecular weight shift on SDS-PAGE. Compared with wild-type and other variants, variant $\mathrm{K} 75 \mathrm{~N} / \mathrm{C} 77 \mathrm{~T} / \mathrm{K} 82 \mathrm{~T}$ showed a clear shift to a higher molecular weight (Fig. 4A), suggesting the incorporation of a glycan. Two additional variants (C66A/K75N/C77T and C66S/K75N/C77T) showed a less pronounced shift to a higher molecular weight (Fig. 4A). All three of these variants have the common mutated sites K75N/C77T. 
TABLE 2

SMAD-responsive luciferase reporter gene assay

Recombinant FS315-hFc variants with either myostatin or activin A were incubated with A204 rhabdomyosarcoma cells stably expressing a SMAD-responsive luciferase reporter construct. The $\mathrm{IC}_{50}$ for each of the variants was determined by fitting the inhibition curve using GraphPad Prism software and is represented as mean \pm S.D. $(n=3)$

\begin{tabular}{lcc}
\hline \multicolumn{1}{c}{ FS315-hFc variant } & $\mathrm{IC}_{50}$ for Myostatin Stimulation & $\mathrm{IC}_{50}$ for Activin A Stimulation \\
\hline & & $\mathrm{nM}$ \\
Wild type & $0.6 \pm 0.03$ & $1.0 \pm 0.02$ \\
Heparin-binding variants & $0.4 \pm 0.02$ & $1.4 \pm 0.1$ \\
SHBS & $>10 *$ & $>10^{*}$ \\
del75-86 & $0.6 \pm 0.01$ & $1.1 \pm 0.02$ \\
K82E & $0.6 \pm 0.09$ & $1.0 \pm 0.2$ \\
K(81,82)E & $0.5 \pm 0.1$ & $1.0 \pm 0.1$ \\
R78E/K82E & $0.7 \pm 0.06$ & $1.1 \pm 0.01$ \\
K(82,84)E & $0.4 \pm 0.03$ & $1.0 \pm 0.1$ \\
K(76,82,84)E & $0.8 \pm 0.07$ & $1.1 \pm 0.1$ \\
K(76,81,82)A & $0.6 \pm 0.03$ & $0.8 \pm 0.01$ \\
K(76,81,82)E & $0.7 \pm 0.03$ & $1.1 \pm 0.1$ \\
K(76,81,82)D & & \\
Hyperglycosylation variants & $0.9 \pm 0.04$ & $1.2 \pm 0.04$ \\
K82T & $0.9 \pm 0.06$ & $1.3 \pm 0.06$ \\
G74N/K76S & $1.8 \pm 0.1$ & $3.7 \pm 0.6$ \\
K75N/C77T/K82T & $1.5 \pm 0.01$ & $2.1 \pm 0.05$ \\
C66A/K75N/C77T & $1.9 \pm 0.09$ & $4.4 \pm 1.2$ \\
C66S/K75N/C77T & & \\
\hline
\end{tabular}

*The $\mathrm{IC}_{50}$ curve was not saturated because of the weak binding.

cIEF data showed that the K75N/C77T/K82T variant had a clear acidic shift of the $\mathrm{pI}$ compared with a K82T variant (Fig. $4 \mathrm{~B}$ ), indicating the potential occupation of a negatively charged glycan moiety at the N75 site causing both the molecular weight and pI shift. To further confirm the status of the glycan occupation on all introduced N-linked glycosylation sites, we performed chromatography- and mass spectrometry-based characterization. Mass spectrometry data confirmed that among the six sites we studied in the heparin-binding loop, we were able to generate hyperglycosylated FS by introducing a glycosylation consensus site on position 75 (Table 4). The three variants, K75N/C77T/K82T, $\mathrm{C} 66 \mathrm{~A} / \mathrm{K} 75 \mathrm{~N} / \mathrm{C} 77 \mathrm{~T}$, and $\mathrm{C} 66 \mathrm{~S} / \mathrm{K} 75 \mathrm{~N} / \mathrm{C} 77 \mathrm{~T}$, containing the same K75N/C77T mutations had variable glycan occupancy $(69.7 \%, 39.6 \%$, and $21.5 \%)$ with similar mole sialic acid/mole oligosaccharide ratios $(1.99,1.88$, and 1.96) on N75 (Table 4). Despite the occupancy difference, the major oligosaccharide species were similar on N75 as well as the three native $\mathrm{N}$-linked sites, including high levels of bi-antennary, triantennary, and tetra-antennary structures, and low levels of high mannose structures (Supplemental Fig. 1). Although the levels of asialylated oligosaccharide at all N-linked sites were comparable for the three hyperglycosylated variants, in general, K75N/C77T/K82T had an overall higher occupancy and a lower asialylated percentage than the other hyperglycosylated variants (Supplemental Fig. 2; Table 4). The overall higher glycosylation occupancy on K75N/C77T/K82T was consistent with its greater mobility shift on polyacrylamide electrophoresis gel (Fig. 4A).

In Vitro Binding Characteristics and In Vivo PK Properties of the Hyperglycosylation Variants. One rationale for designing new hyperglycosylation sites within the HBS region was as an attempt to block heparin binding by introducing negatively charged and bulky glycan structures. For the three hyperglycosylated variants with glycan occupation on N75, in vitro heparin-binding affinity reduction $(\sim 15$ fold reduction compared with wild type) was only observed with variant K75N/C77T/K82T, which had the highest glycan occupancy on N75, as well as a K82T mutation in the second BBXB motif (Supplemental Table 4; Table 5), indicating that the effect of glycan on N75 on heparin-binding activity could be moderate. The three hyperglycosylated variants showed slight or moderate myostatin binding reduction compared with wild type as measured by SPR (Supplemental Table 4; Table 5). In the A204 cell-based reporter assay, the three hyperglycosylated variants had 2-fold to 3 -fold reductions in myostatin inhibition and 2-fold to 4 -fold reductions in activin $\mathrm{A}$ inhibition compared with wild-type and other non-hyperglycosylated variants (Fig. 2B; Table 2), indicating a slight inhibition of potency by the additional glycan.

To determine the effect of hyperglycosylation on PK profiles, we performed mouse PK studies using selected molecules, including non-hyperglycosylated variant K82T, two

\section{TABLE 3}

PK parameters for FS315-hFc variants

CD-1 female mice ( $n=3$ per group) were given a single dose of $1 \mathrm{mg} / \mathrm{kg}$ by intravenous administration. Serum concentrations of the proteins were determined using an electrochemiluminescent immunoassay, and noncompartmental PK analysis PK parameters were calculated. Statistical parameters S.E. and \%CV as calculated by the sparse sampling method are shown for AUC.

\begin{tabular}{|c|c|c|c|c|c|c|}
\hline \multirow{2}{*}{ FS315-hFc Variant } & \multirow{2}{*}{$T_{1 / 2}$} & \multicolumn{3}{|c|}{ AUC } & \multirow{2}{*}{ CL } & \multirow{2}{*}{$\mathrm{V}_{\mathrm{ss}}$} \\
\hline & & Mean & S.E. & $\% \mathrm{CV}$ & & \\
\hline & $\mathrm{h}$ & \multicolumn{3}{|c|}{$h *$ ug per milliliter } & $\begin{array}{l}\mathrm{ml} / \mathrm{h} \text { per } \\
\text { kilogram }\end{array}$ & $\mathrm{ml} / \mathrm{kg}$ \\
\hline Wild type & 68.0 & 29.8 & 0.8 & 2.7 & 30.0 & 1600 \\
\hline$\Delta \mathrm{HBS}$ & 92.1 & 401.0 & 22.2 & 5.5 & 1.3 & 158 \\
\hline K82E & 93.5 & 58.1 & 4.7 & 8.1 & 12.0 & 807 \\
\hline $\mathrm{K} 82 \mathrm{~T}$ & 58.9 & 51.0 & 1.5 & 2.9 & 18.8 & 515 \\
\hline $\mathrm{K}(81,82) \mathrm{A}$ & 80.1 & 114.0 & 3.9 & 3.4 & 8.0 & 385 \\
\hline $\mathrm{K}(81,82) \mathrm{E}$ & 73.5 & 264.0 & 22.0 & 8.3 & 2.7 & 183 \\
\hline $\mathrm{K}(76,82) \mathrm{E}$ & 95.4 & 217.0 & 16.1 & 7.4 & 2.7 & 222 \\
\hline $\mathrm{K}(76,81,82) \mathrm{A}$ & 60.4 & 169.0 & 7.8 & 4.6 & 4.5 & 205 \\
\hline $\mathrm{K}(76,81,82) \mathrm{E}$ & 154.0 & 504.0 & 14.4 & 2.8 & 1.2 & 227 \\
\hline $\mathrm{K}(76,81,82) \mathrm{D}$ & 85.4 & 469.0 & 10.7 & 2.3 & 1.7 & 168 \\
\hline K75N/C77T/K82T & 55.6 & 493.0 & 29.2 & 5.9 & 0.9 & 71 \\
\hline C66A/K75N/C77T & 51.6 & 300.0 & 20.4 & 6.8 & 3.0 & 194 \\
\hline
\end{tabular}

$T_{1 / 2}$, terminal half-life. 

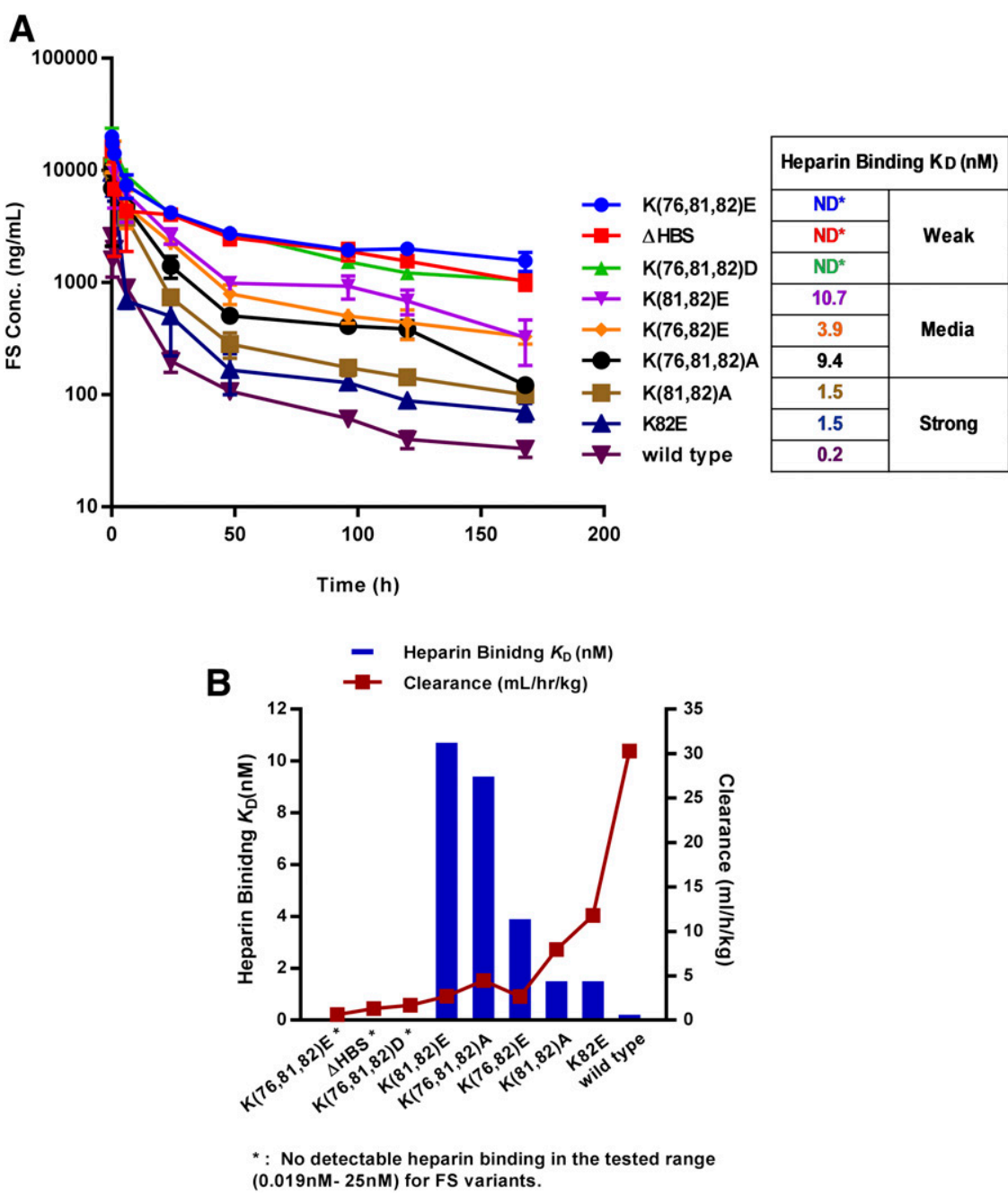

hyperglycosylated variants $\mathrm{K} 75 \mathrm{~N} / \mathrm{C} 77 \mathrm{~T} / \mathrm{K} 82 \mathrm{~T}$ and $\mathrm{C} 66 \mathrm{~A} /$ $\mathrm{K} 75 \mathrm{~N} / \mathrm{C} 77 \mathrm{~T}$, as well as wild-type and $\Delta \mathrm{HBS}$ as controls. $\mathrm{K} 82 \mathrm{~T}, \mathrm{~K} 75 \mathrm{~N} / \mathrm{C} 77 \mathrm{~T} / \mathrm{K} 82 \mathrm{~T}$, and $\mathrm{C} 66 \mathrm{~A} / \mathrm{K} 75 \mathrm{~N} / \mathrm{C} 77 \mathrm{~T}$ were selected for the mouse PK study due to the similarities in glycan structure and distribution, the level of high mannose structure, and the percentage of asialylated structure on the three native N-linked sites for these variants (Supplemental Figs. 1 and 2; Table 4), which enabled us to assess the effect of glycosylation state on the PK profile primarily from the newly introduced $\mathrm{N}$-linked site. Our data show that the nonhyperglycosylated variant K82T had similar but slightly improved PK characteristics compared with wild type. However, the two hyperglycosylated variants had significantly improved PK profiles compared with K82T and wild type (Fig. 5; Table 3). Variant C66A/K75N/C77T showed 6-fold to 10-fold higher exposure, and variant $\mathrm{K} 75 \mathrm{~N} / \mathrm{C} 77 \mathrm{~T} / \mathrm{K} 82 \mathrm{~T}$ showed 10 -fold to 17-fold higher exposure compared with K82T and wild type, which was similar to that of the heparin binding-deficient variant $\triangle$ HBS (Fig. 5; Table 3). The significant difference between the hyperglycosylated variants and the non-hyperglycosylated variant indicate that the increased carbohydrate content directly modulates PK parameters. The $\mathrm{K} 75 \mathrm{~N} / \mathrm{C} 77 \mathrm{~T} / \mathrm{K} 82 \mathrm{~T}$ variant had the highest glycosylation content and sialic acid percentage, as well as weaker heparin binding, which could explain its greater improvement on PK profile than $\mathrm{C} 66 \mathrm{~A} / \mathrm{K} 75 \mathrm{~N} / \mathrm{C} 77 \mathrm{~T}$. Our data above indicate that modulating heparin-binding activity and glycosylation content could be attractive approaches to improve PK properties of FS fusion proteins.

\section{Discussion}

A number of studies have investigated the importance of FSDs and residues on its biologic activities by chemical modifications and mutational analyses (Keutmann et al., 2004; Sidis et al., 2005; Harrison et al., 2006; Zheng et al., 2017). However, systematic protein engineering of recombinant FS for therapeutic applications is largely unexplored. Recently, a recombinant human FS315 variant with the replacement of the HBS region and fused with murine IgG1 Fc has been shown to greatly extend the exposure and half-life in vivo, conferring skeletal muscle hypertrophy and improvement in mouse tissue repair after injury (Datta-Mannan et al., 2013; Yaden et al., 2014). In our study, to further understand the impact that heparin-binding affinity has on molecular properties and PK behavior, we have systematically engineered a series of recombinant FS315 variants fused to $\mathrm{hFc}$ by site-directed mutagenesis.

In this study, we demonstrated that the charge of key residues in the basic BBXB motifs within the FS HBS 

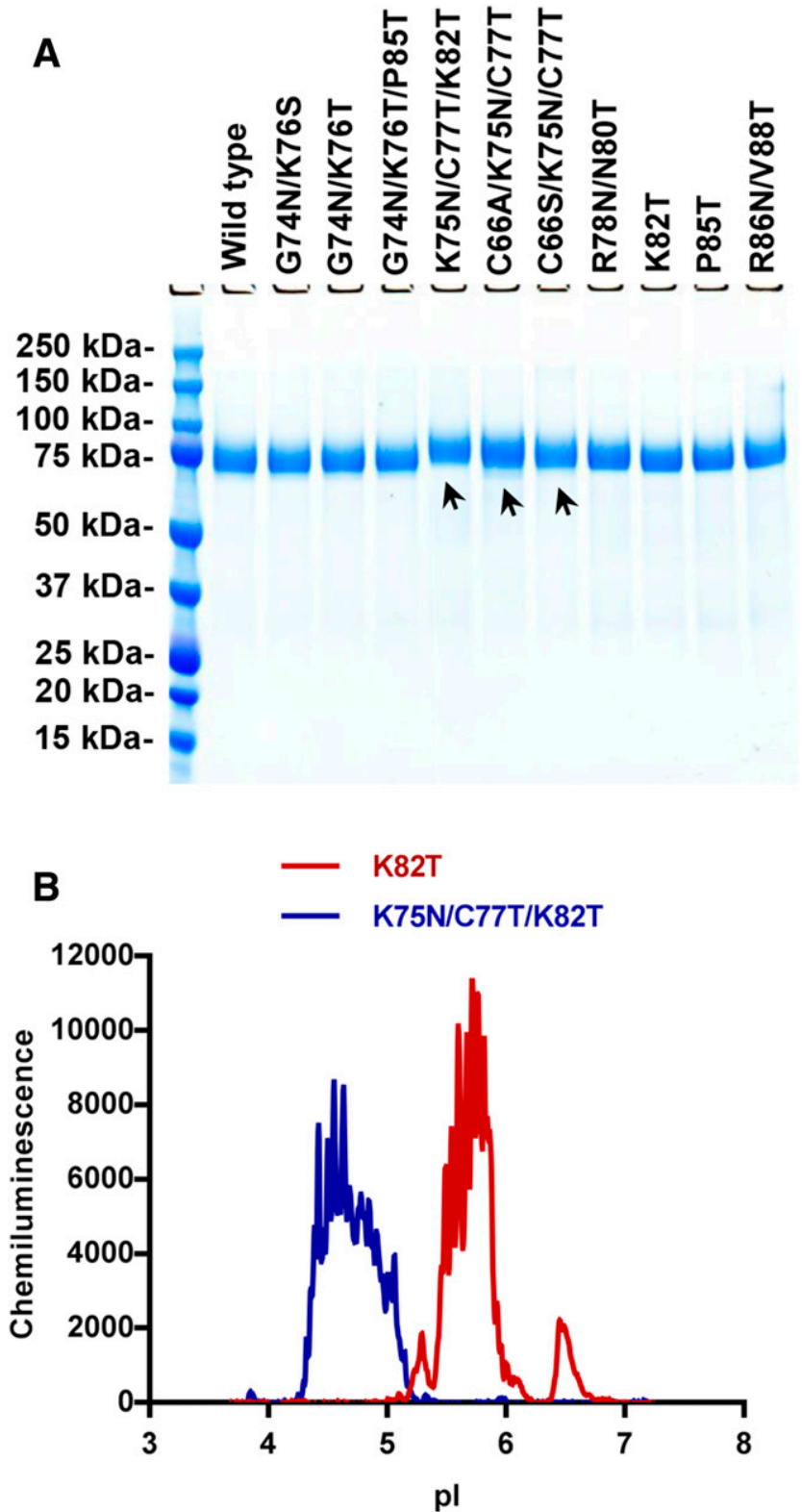

Fig. 4. Hyperglycosylation resulted in a molecular weight and pI shift. (A) Coomassie Blue staining of reduced FS315-hFc hyperglycosylation variants, which were separated by PAGE. Black arrows indicate the variants that showed a clear shift in molecular weight due to hyperglycosylation. (B) cIEF profiles for two representative variants. The hyperglycosylated variant K75N/C77T/K82T (in blue color) showed a clear acidic shift compared with the non-hyperglycosylated variant K82T (in red color).

significantly affect the heparin-binding affinity. FS315 is composed of an N-terminal domain, three FSDs (FSD1, FSD2, and FSD3), and a highly acidic C-terminal tail (Fig. 1). Two core heparin-binding motifs KKCR and KKNK that are rich in basic residues are located in the FSD1, which makes it the most basic domain (pI 8.9) compared with FSD2 (pI 6.7) and FSD3 (pI 4.8) (Innis and Hyvonen, 2003). Structural analysis of 20 nonredundant three-dimensional protein structures in complex with heparin showed that electrostatic and hydrogen-bonding interactions contribute the most in the binding between cationic residues ( $\mathrm{K}$ or $\mathrm{R}$ ) and anionic groups in heparin (Torrent et al., 2012). A crystal structure of the FS FSD1 domain complexed with heparin analogs also indicated that heparin analogs associate with the highly basic HBS through their negatively charged sulfate groups by electrostatic interactions (Innis and Hyvonen, 2003). We hypothesized that substituting cationic residues with anionic residues in the BBXB motifs of the HBS region will break the electrostatic interactions and abolish heparin binding. Indeed, our negative residue-substituted variants $\mathrm{K}$ $(76,81,82) \mathrm{E}$ and $\mathrm{K}(76,81,82) \mathrm{D}$ had undetectable heparinbinding affinities in SPR binding assays, whereas a neutral residue-substituted variant $\mathrm{K}(76,81,82) \mathrm{A}$ had a binding $K_{\mathrm{D}}$ of $9.4 \mathrm{nM}$, confirming the greater effect on eliminating heparin binding using negatively charged substitutions. With the significant impact of negatively charged substitutions on heparin-binding affinity, we were able to make only a few point mutations to achieve the same change in binding as seen with the HBS replacement variant $\triangle \mathrm{HBS}$ and the HBS deletion variant del75-86 (Table 1). In our hands, using minimal substitutions allowed for improved expression levels for our FS variants in $\mathrm{CHO}$ cells and reduced protein aggregation in our protein A eluate, as well as retained similar activin $\mathrm{A}-$ and myostatin-binding affinities as wild type.

By generating a series of one, two, or three amino acid substitutions for the key residues in the BBXB motifs using the negatively charged residue glutamic acid $\mathrm{E}$, we were able to: 1) identify the key positions and combinations for heparin binding. Our screening of six basic residues in the two BBXB motifs indicated that K81 and K82 in the second BBXB motif play a dominant role for the electrostatic interaction since we observed the highest impact on heparin binding with the doublet variant $\mathrm{K}(81,82) \mathrm{E}$ compared with six other doublet variants, including $\mathrm{K}(75,76) \mathrm{E}, \mathrm{K}(76,82) \mathrm{E}, \mathrm{K}(76,84) \mathrm{E}$, R78E/ $\mathrm{K} 82 \mathrm{E}, \mathrm{R} 78 \mathrm{E} / \mathrm{K} 84 \mathrm{E}$, and $\mathrm{K}(82,84) \mathrm{E}$ (Table 1). Interestingly, we also found that variants with the K82E mutation consistently showed an $\sim 2$-fold increase in protein expression levels (data not shown), implying the positive impact of K82E on protein folding; and 2) generate variants with different degrees of heparin binding, having a range of 4 -fold to $>100$-fold reduction in our testing range compared with wild type. It has been shown that the association between FS and cell surface heparan sulfate proteoglycans caused rapid cellular uptake and CL (Hashimoto et al., 1997). Since it was of interest to us how the different degree of in vitro heparin binding correlated with in vivo PK profiles, we selected multiple variants with different heparin-binding affinities, and administered them as a single intravenous dose $(1 \mathrm{mg} / \mathrm{kg})$ to female CD1 mice. All of the variants showed improved PK profiles compared with wild type and, more strikingly, decreased heparin-binding clearly correlated with increased AUC and decreased CL (Fig. 3; Table 3). The significantly decreased apparent volumes of distribution for heparin-binding variants, which were reflected in $\mathrm{V}_{\mathrm{ss}}$ (Table 3 ), strongly support that the association with cell surface heparan sulfate proteoglycans is one of the determinant processes for the in vivo PK profile of FS protein. In contrast with the clear relationship between heparinbinding affinity and either AUC or CL, we did not see this direct relationship on the terminal half-life. Compared with the significant impact of heparin-binding affinity on the distribution phase, the terminal half-life was mainly driven by elimination pathways, such as FcRn-dependent interaction for recombinant Fc-fusion proteins; and 3) retain unchanged ligand binding potency compared with wild type (Fig. 2A; 
TABLE 4

Characterization of endogenous and hyperglycosylated N-linked glycosylation sites

Percentage glycan occupancy and sialic acid content are shown.

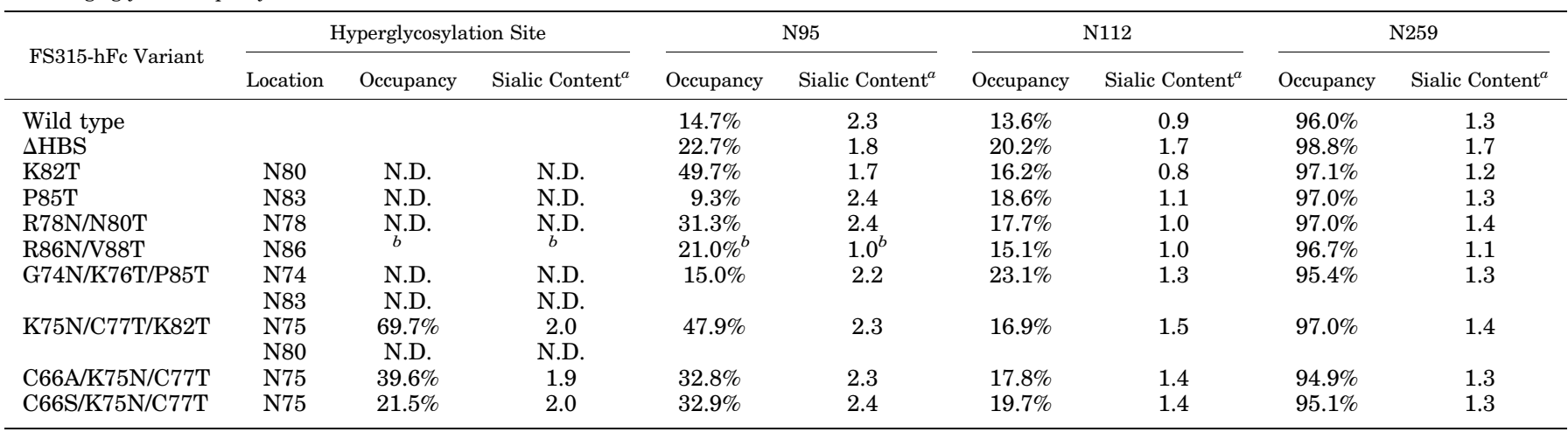

N.D., not determined.

${ }^{a}$ mol sialic acid per mol oligosaccharide.

${ }^{b}$ Results do not distinguish glycosylation at N86 or N95.

Table 2), which supports published studies that both $\mathrm{N}$-terminal domain and FSD2 may be the essential determinants for either myostatin or activin binding (Keutmann et al., 2004; Zheng et al., 2017).

Our heparin-binding variants with introduced negative residues have lower $\mathrm{pI}$ values than wild type. Published work (Igawa et al., 2010; Li et al., 2014) demonstrated that an antibody with a lower pI had a longer half-life, which was proposed to be due to a decreased level of fluid-phase pinocytosis. This is consistent with our negatively charged heparin-binding variants having reduced association with cell surface heparan sulfate proteoglycans, therefore, having a reduced cellular uptake and CL.

Glycoengineering technology is becoming an attractive strategy to improve the pharmaceutical properties of therapeutic agents. There are many approaches for glycoengineering, including the introduction of new glycosylation sites to increase carbohydrate content or to block specific binding (Yu et al., 2017; Mimura et al., 2018). In this study, we generated 10 variants with six new consensus $\mathrm{N}$-linked glycosylation sites within the HBS region. Among the designed six positions, we were able to identify a hyperglycosylation site on N75
(Table 4). The crystal structure of FSD1 indicates that residues $64-74$ form a loop, followed by strand $\beta 1$ (residues $75-79$ ) and strand $\beta 2$ (residues $85-89$ ). Residue 75 locates in a type II $\beta$-turn (residues 72-75), which connects the loop and strand $\beta 1$ (Innis and Hyvonen, 2003), which is consistent with the finding that glycosylation is often occurring at an exposed loop region with some flexibility (Samoudi et al., 2015). Interestingly, not much glycan occupancy was observed on the neighboring site N74 (Table 4), suggesting the potential importance of three-dimensional structures on glycosylation.

Glycosylation is the most complex post-translational process. During the production process, various parameters impact glycan structures, including cell culture conditions, protein structure, and protein folding. Methods to modulate glycosylation heterogeneity for glycoproteins in mammalian cell culture have been well documented during the manufacturing process, including optimizing $\mathrm{pH}$, temperature, oxygen concentration, the medium formulation and feed rate, expression level, and production method (batch, fedbatch, perfusion) (Hossler, 2012). In our study, we used consistent expression and culture conditions for our variants to reduce glycosylation heterogeneity caused by the culture

TABLE 5

In vitro analytical data for hyperglycosylation variants of FS315-hFc

The recombinant FS315-hFc variants with newly designed one or two NXT/Ss are listed in the table. The binding of the variants to heparin, myostatin, or $\mathrm{hFcRn}$ was determined by SPR. The binding affinities were measured and reported by the $K_{\mathrm{D}}$. The charge heterogeneity of the variants was determined by cIEF and shown as the range of pI values. The statistical parameters and analysis, including association constant $\left(k_{\mathrm{a}}\right)$ with S.E., dissociation constant $\left(k_{\mathrm{d}}\right)$ with S.E., and the average $K_{\mathrm{D}}$ values with S.D. ( $n=4$ independent batches) for an internal control used in all SPR assays, are reported in Supplemental Table 4.

\begin{tabular}{lcccc}
\hline FS315-hFc Variant & Heparin Binding $K_{\mathrm{D}}$ & Myostatin Binding $K_{\mathrm{D}}$ & $\mathrm{hFcRn}$ Binding $K_{\mathrm{D}}$ & $\mathrm{cIEF}$ \\
\hline & $\mathrm{nM}$ & $\mathrm{pM}$ & $\mathrm{nM}$ & $\mathrm{pI}$ \\
Wild type & 0.2 & 20.2 & 28.3 & $5.07-5.89$ \\
K82T & 1.4 & 15.0 & 13.8 & $5.29-5.93$ \\
P85T & 0.4 & 12.4 & 20.1 & $5.51-6.09$ \\
R78N/N80T & 0.9 & 13.0 & 20.1 & $5.47-6.09$ \\
R86N/V88T & 1.5 & 12.7 & 10.8 & $5.49-6.08$ \\
G74N/K76S & 0.3 & 11.6 & 42.8 & $5.06-5.88$ \\
G74N/K76T & 0.5 & 11.1 & 29.6 & $5.06-5.99$ \\
G74N/K76T/P85T & 0.3 & 11.6 & 36.2 & $4.86-5.87$ \\
K75N/C77T/K82T & 3.5 & 40.3 & 27.5 & $4.72-5.88$ \\
C66A/K75N/C77T & 0.3 & 24.4 & 82.8 & $4.86-6.47$ \\
C66S/K75N/C77T & 0.4 & 26.0 & & \\
\hline
\end{tabular}




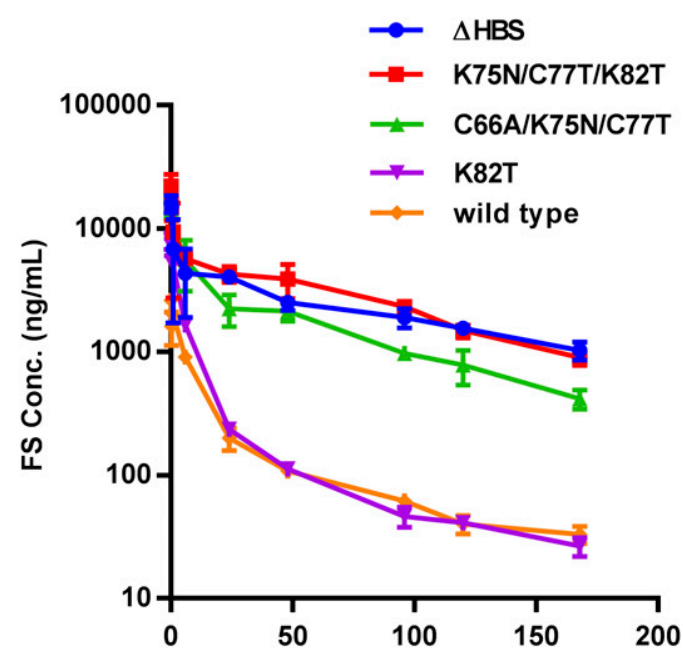

Time (h)

Fig. 5. PK profiles for FS315-hFc hyperglycosylation variants. Mice were given a single dose of $1 \mathrm{mg} / \mathrm{kg}$ protein by intravenous administration $(n=$ 3 per group). The hyperglycosylated variants $\mathrm{K} 75 \mathrm{~N} / \mathrm{C} 77 \mathrm{~T} / \mathrm{K} 82 \mathrm{~T}$ and C66A/K75N/C77T had significantly improved PK profiles over the nonhyperglycosylated variant K82T, as well as wild type. The variant K75N/ C77T/K82T showed a comparable PK profile compared with the HBS deficient mutant $\triangle$ HBS. Conc., concentration.

environment. We observed consistent high occupancy on N259; however, both N95 and N112 were variably occupied for different FS315-hFc variants (Table 4). Although varied in occupancy, the major glycan species and their abundances at each N-linked site were similar for different FS315-hFc variants (Supplemental Fig. 1 and data not shown). For example, at N95, the most abundant glycan species were tetra-antennary, tri-antennary, and bi-antennary complex oligosaccharides with sialic acids fully or partially occupied at the terminal (Supplemental Fig. 2). For simplification, the sialic acid content was chosen to evaluate the overall terminal sialic acid level in different variants in this study. It has been reported that poorly sialylated recombinant FS proteins had a quicker CL because of asialoglycoprotein receptor-mediated CL (Datta-Mannan et al., 2015). Two hyperglycosylated variants $\mathrm{K} 75 \mathrm{~N} / \mathrm{C} 77 \mathrm{~N} / \mathrm{K} 82 \mathrm{~T}$ and $\mathrm{C} 66 \mathrm{~A} / \mathrm{K} 75 \mathrm{~N} / \mathrm{C} 77 \mathrm{~T}$ showed significantly improved in vivo exposure compared with wildtype and non-hyperglycosylated variant K82T in mouse studies (Fig. 5), indicating that the glycan occupancy on new introduced $\mathrm{N}$-linked site may have increased sialic acid content, and could block some heparin binding by the addition of a bulky glycan in vivo. Our data suggest that the addition of a hyperglycosylation modification could be a surgical approach to the HBS variants to achieve further improved PK properties and reduce the immunogenicity risk.

In summary, the data collected from our engineered FS315$\mathrm{hFc}$ recombinant variants focused on the manipulation of heparin-binding affinity and the evaluation of the impact of the mutations on PK properties. This comprehensive study provides valuable information for potential pharmacologic application of improved recombinant FS molecules. Certain selected variants, such as $\mathrm{K}(76,81,82) \mathrm{E}$, showed promising pharmacodynamics in pharmacology studies (Shire, manuscript in preparation). Manipulating heparin-binding activity, glycosylation content, and/or the myostatin binding affinity by protein engineering could be attractive strategies for generating novel molecules with desirable therapeutic properties. Further studies should be considered to explore a clear exposure-response relationship for these novel variants in the content of different therapeutic applications.

\section{Acknowledgments}

We thank the present and former members of the project team at Shire for helpful discussions during this study. We also thank Brian K. Miller and Jun $\mathrm{Hu}$ for technical support during this study.

\section{Authorship Contributions}

Participated in research design: Shen, Iskenderian, Gill, Zhang, Meiyappan, Pan, and Norton.

Conducted experiments: Shen, Iskenderian, Lundberg, He, Palmieri, Crooker, Deng, Traylor, Gu, Pescatore, Strack-Logue, Romashko, and Baviello.

Performed data analysis: Palmieri, Crooker, Traylor, and Rong.

Wrote or contributed to the writing of the manuscript: Shen, Iskenderian, Lundberg, He, Palmieri, Deng, Traylor, Rong, Ehmann, Zhang, Meiyappan, Pan, and Norton.

\section{References}

Bernfield M, Götte M, Park PW, Reizes O, Fitzgerald ML, Lincecum J, and Zako M (1999) Functions of cell surface heparan sulfate proteoglycans. Annu Rev Biochem 68:729-777.

Cash JN, Angerman EB, Keutmann HT, and Thompson TB (2012) Characterization of follistatin-type domains and their contribution to myostatin and activin A antagonism. Mol Endocrinol 26:1167-1178.

Chen PR and Lee K (2016) Invited review: inhibitors of myostatin as methods of enhancing muscle growth and development. J Anim Sci 94:3125-3134.

Datta-Mannan A, Huang L, Pereira J, Yaden B, Korytko A, and Croy JE (2015) Insights into the impact of heterogeneous glycosylation on the pharmacokinetic behavior of follistatin-Fc-based biotherapeutics. Drug Metab Dispos 43:1882-1890.

Datta-Mannan A, Yaden B, Krishnan V, Jones BE, and Croy JE (2013) An engineered human follistatin variant: insights into the pharmacokinetic and pharmocodynamic relationships of a novel molecule with broad therapeutic potential. $J$ Pharmacol Exp Ther 344:616-623.

Dennler S, Itoh S, Vivien D, ten Dijke P, Huet S, and Gauthier JM (1998) Direct binding of Smad3 and Smad4 to critical TGF beta-inducible elements in the promoter of human plasminogen activator inhibitor-type 1 gene. $E M B O J$ 17: $3091-3100$

Esch FS, Shimasaki S, Mercado M, Cooksey K, Ling N, Ying S, Ueno N, and Guillemin R (1987) Structural characterization of follistatin: a novel folliclestimulating hormone release-inhibiting polypeptide from the gonad. Mol Endocrinol 1:849-855.

Haidet AM, Rizo L, Handy C, Umapathi P, Eagle A, Shilling C, Boue D, Martin PT, Sahenk Z, Mendell JR, et al. (2008) Long-term enhancement of skeletal muscle mass and strength by single gene administration of myostatin inhibitors. Proc Natl Acad Sci USA 105:4318-4322.

Harrison CA, Chan KL, and Robertson DM (2006) Activin-A binds follistatin and type II receptors through overlapping binding sites: generation of mutants with isolated binding activities. Endocrinology 147:2744-2753.

Hashimoto O, Nakamura T, Shoji H, Shimasaki S, Hayashi Y, and Sugino H (1997) A novel role of follistatin, an activin-binding protein, in the inhibition of activin action in rat pituitary cells. Endocytotic degradation of activin and its acceleration by follistatin associated with cell-surface heparan sulfate. J Biol Chem 272: 13835-13842.

Hossler P (2012) Protein glycosylation control in mammalian cell culture: past precedents and contemporary prospects. Adv Biochem Eng Biotechnol 127: $187-219$

Igawa T, Tsunoda H, Tachibana T, Maeda A, Mimoto F, Moriyama C, Nanami M, Sekimori Y, Nabuchi Y, Aso Y, et al. (2010) Reduced elimination of IgG antibodies by engineering the variable region. Protein Eng Des Sel 23:385-392.

Innis CA and Hyvönen M (2003) Crystal structures of the heparan sulfate-binding domain of follistatin. Insights into ligand binding. J Biol Chem 278:39969-39977.

Inouye S, Ling N, and Shimasaki S (1992) Localization of the heparin binding site of follistatin. Mol Cell Endocrinol 90:1-6.

Jefferis R (2016) Glyco-engineering of human IgG-Fc to modulate biologic activities. Curr Pharm Biotechnol 17:1333-1347.

Keutmann HT, Schneyer AL, and Sidis Y (2004) The role of follistatin domains in follistatin biological action. Mol Endocrinol 18:228-240.

Kota J, Handy CR, Haidet AM, Montgomery CL, Eagle A, Rodino-Klapac LR, Tucker D, Shilling CJ, Therlfall WR, Walker CM, et al. (2009) Follistatin gene delivery enhances muscle growth and strength in nonhuman primates. Sci Transl Med $\mathbf{1}$ : $6 \mathrm{ra} 15$.

Lalonde ME and Durocher Y (2017) Therapeutic glycoprotein production in mammalian cells. J Biotechnol 251:128-140.

Latres E, Pangilinan J, Miloscio L, Bauerlein R, Na E, Potocky TB, Huang Y, Eckersdorff M, Rafique A, Mastaitis J, et al. (2015) Myostatin blockade with a fully human monoclonal antibody induces muscle hypertrophy and reverses muscle atrophy in young and aged mice. Skelet Muscle 5:34. 
Lee SJ, Reed LA, Davies MV, Girgenrath S, Goad ME, Tomkinson KN, Wright JF, Barker C, Ehrmantraut G, Holmstrom J, et al. (2005) Regulation of muscle growth by multiple ligands signaling through activin type II receptors. Proc Natl Acad Sci USA 102:18117-18122.

Li B, Tesar D, Boswell CA, Cahaya HS, Wong A, Zhang J, Meng YG, Eigenbrot C, Pantua H, Diao J, et al. (2014) Framework selection can influence pharmacokinetics of a humanized therapeutic antibody through differences in molecule charge. MAbs 6:1255-1264.

Mendell JR, Sahenk Z, Al-Zaidy S, Rodino-Klapac LR, Lowes LP, Alfano LN, Berry K, Miller N, Yalvac M, Dvorchik I, et al. (2017) Follistatin gene therapy for sporadic inclusion body myositis improves functional outcomes. Mol Ther 25: 870-879.

Mendell JR, Sahenk Z, Malik V, Gomez AM, Flanigan KM, Lowes LP, Alfano LN, Berry K, Meadows E, Lewis S, et al. (2015) A phase $1 / 2$ a follistatin gene therapy trial for becker muscular dystrophy. Mol Ther 23:192-201.

Mimura Y, Katoh T, Saldova R, O'Flaherty R, Izumi T, Mimura-Kimura Y, Utsunomiya T, Mizukami Y, Yamamoto K, Matsumoto T, et al. (2018) Glycosylation engineering of therapeutic IgG antibodies: challenges for the safety, functionality and efficacy. Protein Cell 9:47-62.

Nakamura T, Sugino K, Titani K, and Sugino H (1991) Follistatin, an activin-binding protein, associates with heparan sulfate chains of proteoglycans on follicular granulosa cells. J Biol Chem 266:19432-19437.

Namwanje M and Brown CW (2016) Activins and inhibins: roles in development physiology, and disease. Cold Spring Harb Perspect Biol 8:a021881.

Robertson DM, Klein R, de Vos FL, McLachlan RI, Wettenhall RE, Hearn MT, Burger HG, and de Kretser DM (1987) The isolation of polypeptides with FSH suppressing activity from bovine follicular fluid which are structurally different to inhibin. Biochem Biophys Res Commun 149:744-749.

Rodino-Klapac LR, Haidet AM, Kota J, Handy C, Kaspar BK, and Mendell JR (2009) Inhibition of myostatin with emphasis on follistatin as a therapy for muscle disease. Muscle Nerve 39:283-296.

Sako D, Grinberg AV, Liu J, Davies MV, Castonguay R, Maniatis S, Andreucci AJ, Pobre EG, Tomkinson KN, Monnell TE, et al. (2010) Characterization of the ligand binding functionality of the extracellular domain of activin receptor type IIb. J Biol Chem 285:21037-21048.

Samoudi M, Tabandeh F, Minuchehr Z, Ahangari Cohan R, Nouri Inanlou D, Khodabandeh M, and Sabery Anvar M (2015) Rational design of hyper-glycosylated interferon beta analogs: a computational strategy for glycoengineering. $J \mathrm{Mol}$ Graph Model 56:31-42.

Schneyer AL, Wang Q, Sidis Y, and Sluss PM (2004) Differential distribution of follistatin isoforms: application of a new FS315-specific immunoassay. $J$ Clin Endocrinol Metab 89:5067-5075.

Schuelke M, Wagner KR, Stolz LE, Hübner C, Riebel T, Kömen W, Braun T, Tobin JF, and Lee SJ (2004) Myostatin mutation associated with gross muscle hypertrophy in a child. $N$ Engl $J$ Med 350:2682-2688.
Shimasaki S, Koga M, Esch F, Cooksey K, Mercado M, Koba A, Ueno N, Ying SY, Ling N, and Guillemin R (1988) Primary structure of the human follistatin precursor and its genomic organization. Proc Natl Acad Sci USA 85:4218-4222.

Sidis Y, Mukherjee A, Keutmann H, Delbaere A, Sadatsuki M, and Schneyer A (2006) Biological activity of follistatin isoforms and follistatin-like-3 is dependent on differential cell surface binding and specificity for activin, myostatin, and bone morphogenetic proteins. Endocrinology 147:3586-3597.

Sidis Y, Schneyer AL, and Keutmann HT (2005) Heparin and activin-binding determinants in follistatin and FSTL3. Endocrinology 146:130-136.

St Andre M, Johnson M, Bansal PN, Wellen J, Robertson A, Opsahl A, Burch PM, Bialek P, Morris C, and Owens J (2017) A mouse anti-myostatin antibody increases muscle mass and improves muscle strength and contractility in the mdx mouse mode of Duchenne muscular dystrophy and its humanized equivalent, domagrozumab (PF06252616), increases muscle volume in cynomolgus monkeys. Skelet Muscle 7:25

Sugino K, Kurosawa N, Nakamura T, Takio K, Shimasaki S, Ling N, Titani K, and Sugino H (1993) Molecular heterogeneity of follistatin, an activin-binding protein. Higher affinity of the carboxyl-terminal truncated forms for heparan sulfate proteoglycans on the ovarian granulosa cell. J Biol Chem 268:15579-15587.

Torrent M, Nogués MV, Andreu D, and Boix E (2012) The "CPC clip motif": a conserved structural signature for heparin-binding proteins. PLoS One 7:e42692.

Traylor MJ, Tchoudakova AV, Lundquist AM, Gill JE, Boldog FL, and Tangarone BS (2016) Comprehensive discovery and quantitation of protein heterogeneity via LC-MS/MS peptide mapping for clone selection of a therapeutic protein. Anal Chem 88:9309-9317.

Ueno N, Ling N, Ying SY, Esch F, Shimasaki S, and Guillemin R (1987) Isolation and partial characterization of follistatin: a single-chain $\mathrm{Mr}$ 35,000 monomeric protein that inhibits the release of follicle-stimulating hormone. Proc Natl Acad Sci USA 84: $8282-8286$

Walton KL, Johnson KE, and Harrison CA (2017) Targeting TGF- $\beta$ mediated SMAD signaling for the prevention of fibrosis. Front Pharmacol 8:461.

Welt C, Sidis Y, Keutmann H, and Schneyer A (2002) Activins, inhibins, and follistatins: from endocrinology to signaling. A paradigm for the new millennium. Exp Biol Med (Maywood) 227:724-752.

Yaden BC, Croy JE, Wang Y, Wilson JM, Datta-Mannan A, Shetler P, Milner A, Bryant HU, Andrews J, Dai G, et al. (2014) Follistatin: a novel therapeutic for the improvement of muscle regeneration. J Pharmacol Exp Ther 349:355-371.

Yu X, Marshall MJE, Cragg MS, and Crispin M (2017) Improving antibody-based cancer therapeutics through glycan engineering. BioDrugs 31:151-166.

Zheng H, Qiao C, Tang R, Li J, Bulaklak K, Huang Z, Zhao C, Dai Y, Li J, and Xiao X (2017) Follistatin $\mathrm{N}$ terminus differentially regulates muscle size and fat in vivo. Exp Mol Med 49:e377.

Address correspondence to: Angela W. Norton, Discovery Therapeutics, Shire, 300 Shire Way, Lexington, MA 02421. E-mail: anorton@shire.com 